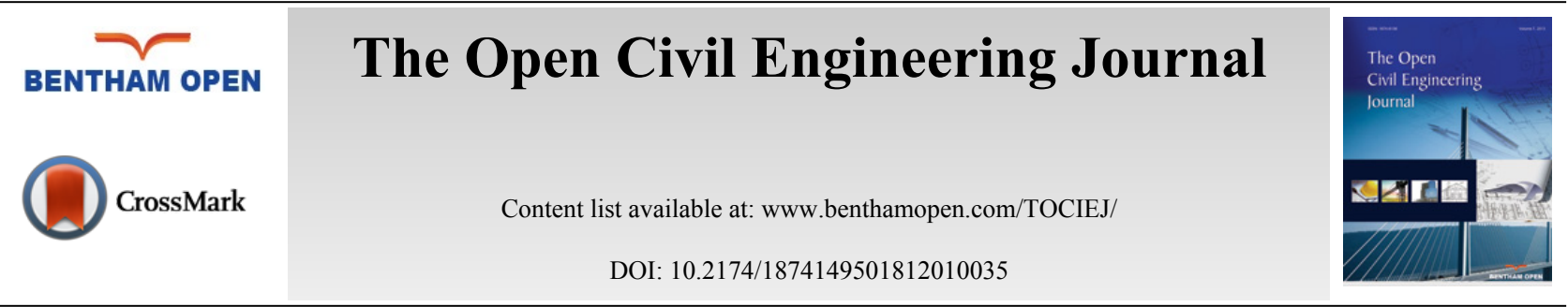

RESEARCH ARTICLE

\title{
Workability, Setting Time and Strength of High-Strength Concrete Containing High Volume of Palm Oil Fuel Ash
}

\author{
A.M. Zeyad ${ }^{1}$, Bassam A. Tayeh ${ }^{2, *}$, Abdalla M. Saba ${ }^{3}$ and M.A. Megat Johari ${ }^{4}$ \\ ${ }^{\prime}$ Department of Civil Engineering, Jazan University, Jazan, Saudi Arabia \\ ${ }^{2}$ Civil Engineering Department, Islamic University of Gaza, Gaza, Palestine \\ ${ }^{3}$ Department of materials Engineering, Zagazig University, Zagazig, Egypt \\ ${ }^{4}$ School of Civil Engineering, Universiti Sains Malaysia, Penang, Malaysia
}

\section{Abstract:}

\section{Introduction:}

Palm oil fuel ash in two various forms-ground (GPOFA) by heat-treated carbon-free ultrafine of a median particle size of $2 \mu \mathrm{m}$ (UPOFA) were utilized to produce high strength concretes (HSC-GPOFA ( $\left.\mathrm{HSCg}_{\mathrm{x}}\right), \mathrm{HSC}-\mathrm{UPOFA}(\mathrm{HSCu})$, and HSC-OPC) at different levels ordinary Portland cement (OPC) partial replacements (x) of 20, 40 and 60\%.

\section{Methods:}

The workability (slump, slump loss, and compacting factor), initial and final setting times and strength in both forms of concrete were investigated.

\section{Results and Conclusion:}

The results showed that $\mathrm{HSCu}$ had improved physical properties and chemical compositions, extended setting times, enhanced workability, better strength, and enhanced workability retention compared to HSCg and HSC-OPC. Further, POFA carbon content negatively influenced the workability and setting time, while its specific gravity had a positive influence due to the enhancement of paste volume and particles lubrication effects. However, carbon content and surface areas of POFA did not significantly influence the compressive strength of HSC at the level of partial OPC substitution not exceeding $40 \%$.

Keywords: Compressive Strength, Fresh Concrete Properties, Heat treatment, High Strength Concrete, Palm Oil Fuel Ash, Workability.

\section{INTRODUCTION}

Workability is one of the significant characteristics of high-strength concrete because such concrete is produced using a low water-cementitious ratio. Thus, extensive utilization of high range water reducer is necessary in order to attain the required rheological characteristics to facilitate mixing, transporting, placing and compacting. These processes also indicate the necessity for adequate workability retention of the concrete as untimely set concrete may have proper placing challenges. The dosage, type of superplasticizer and cement chemical compositions affect the workability and other characteristics of fresh concrete [1]. Furthermore, time of concreting, temperatures, wind velocity and relative humidity directly affect the rheology of concrete due to depletion of free water available in the paste [2]. The hydration of cement and depletion of free water will lead to an increase in slump loss. Supplementary cementitious materials (SCMs) have various effects on properties of fresh concrete [3,4] which depend on many variables such as

* Address correspondence to this author at the Civil Engineering Department, Islamic University of Gaza, Gaza, Palestine; Tel: +972-82644400; Fax: +972-82644800; E-mail: btayeh@iugaza.edu.ps 
the chemical compositions and physical properties of the binders [5, 6]. Moreover, the use of mineral admixtures in high-strength concrete to partially replace cement could somehow contribute towards improving the properties of fresh concrete [7 - 10]. The general effects of mineral admixtures increase the slump, compacting factor, delay the initial and final setting and lessen the loss in slump [9, 11]. In addition, the inclusion of some of mineral admixture such as fly ash and POFA as partial replacement of cement reduces the water demand in the high-strength concrete, and this works to increase workability at constant water-cementitious ratio and superplasticizer dosage. The particle shape or geometry of the mineral admixture may help increase workability. Whenever there are more spherical particles, which contribute to the "ball-bearing effect" that enhances inter-particle mobility [9, 12], the workability increases. Further, well distributed fine particles in concrete help to reduce the friction between the aggregates and thereby improving the workability. Increase in paste volume also contributes to cohesion and compaction [13]. Furthermore, palm oil fuel ash waste is one of the pozzolanic materials, which has higher carbon content in its original state. The unburned carbon content in mineral admixture leads to disruption of the efficiency of super-plasticizer, causing reduced fluidity and workability [9]. Utilization of POFA after grinding and removing unburned carbon as pozzolanic mineral admixture in concrete could have a positive impact on the properties of fresh high strength concrete (HSC) [14, 15]. The present study investigates the impacts of carbon-laden POFA (GPOFA) on workability, setting times and compressive strength of HSC in comparison with ultrafine carbon-free type (UPOFA) at multiple levels of POFA-cement replacement of $0,20,40$ and $60 \%$ by mass. The importance of this study is helping to absorb waste produced from Palm oil tree.

\section{MATERIALS AND METHODOLOGY}

\subsection{Materials}

The POFA used in this research was obtained from Nibong-Tebal palm oil mill. It was first oven-dried at $105 \pm 5^{\circ} \mathrm{C}$ for $24 \mathrm{~h}$ for moisture removal and then passed on sieve slots size of a $0.30 \mathrm{~mm}$ to separate coarser particles and the wreckage. The POFA was then grounded using a laboratory scale ball-mill to produce ground POFA (GPOFA) as shown in Fig. (1a). However, in order to get rid of unburned carbon, the GPOFA was heated in a gas furnace at $500 \pm 50$ ${ }^{\circ} \mathrm{C}$ for 90 mins to produce treated POFA (TPOFA) [15]. This method was similar to that reported by [12], by removing excessive unburned carbon but without having the second stage grinding by the same ball mill to get the ultra-fine POFA (UPOFA) as shown in Fig. (1b).

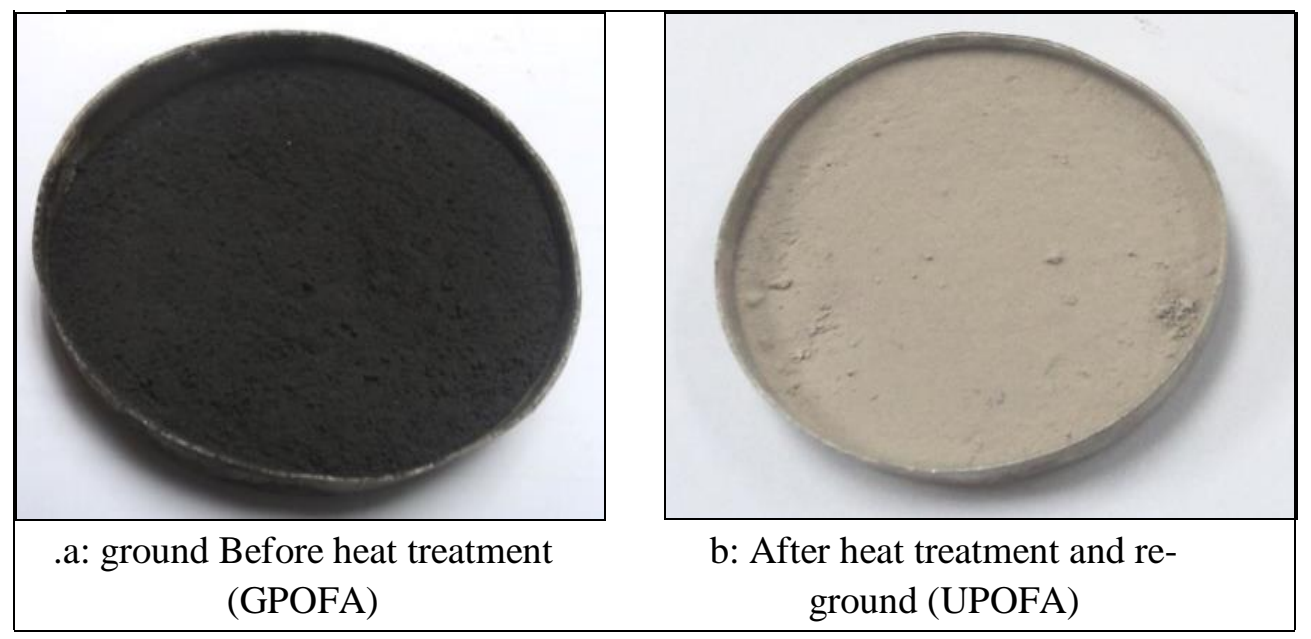

Fig. (1). Ground palm oil fuel ash (GPOFA and ultrafine or treated palm oil fuel ash (UPOFA).

Ordinary Portland cement (OPC) has properties comply with the requirements of ASTM C150 [16] which was used to produce the HSC containing the POFA in addition to natural river sand, crushed granite, water and type $\mathrm{F}$ of the superplasticizer. The natural river sand and the crushed granite properties are shown in Table $\mathbf{1}$.

Table 1. Aggregate properties.

\begin{tabular}{|c|c|c|c|c|}
\hline Materials & $\begin{array}{c}\text { Specific gravity } \\
\left(\mathbf{g} / \mathbf{c m}^{\mathbf{3}}\right)\end{array}$ & Water absorption (\%) & Value of aggregate crushing (\%) & $\begin{array}{c}\text { bulk density } \\
\left(\mathbf{k g} / \mathbf{m}^{3}\right)\end{array}$ \\
\hline Natural river sand & 2.7 & 0.62 & - & - \\
\hline
\end{tabular}


(Table 1) contd.....

\begin{tabular}{|c|c|c|c|c|}
\hline Materials & $\begin{array}{c}\text { Specific gravity } \\
\left(\mathbf{g} / \mathbf{c m}^{\mathbf{3}}\right)\end{array}$ & Water absorption $(\mathbf{\%})$ & $\begin{array}{c}\text { Value of aggregate crushing }(\%) \\
\text { bulk density } \\
\left(\mathbf{k g} / \mathbf{m}^{\mathbf{3}}\right)\end{array}$ \\
\hline Crushed granite & 2.51 & 0.48 & $17.2 \%$ \\
\hline
\end{tabular}

\subsection{Mix Proportions and Samples Preparation}

The mixed proportions for the HSC were derived depending on the classification recommended by American concrete institute (ACI 211-4R) [1, 17] as shown in Table 2. For the HSC-UPOFA (HSCu) and HSC-GPOFA (HSCg) with the cement partly replaced by mass with UPOFA and GPOFA, respectively while other component materials remain the same. The samples were removed from the molds after $24 \mathrm{~h}$ after casting, and then cured in a water tank at room temperature of $27 \pm 2{ }^{\circ} \mathrm{C}$ until applied the tests.

Table 2. Concrete mix proportions for HSC-OPC, HSCg and HSCu.

\begin{tabular}{|c|c|c|c|c|}
\hline Materials $\left(\mathbf{k g} / \mathbf{m}^{\mathbf{3}}\right)$ & \multicolumn{4}{|c|}{ Concrete Mix } \\
\hline & OPC & POFA20 & POFA40 & POFA60 \\
\hline OPC & 550 & 440 & 330 & 220 \\
\hline POFA & 0 & 110 & 220 & 330 \\
\hline Granite & 1033.6 & 1033.6 & 1033.6 & 1033.6 \\
\hline River sand & 741.2 & 741.2 & 741.2 & 741.2 \\
\hline Water & 148.9 & 148.9 & 148.9 & 148.9 \\
\hline Superplasticiser & 12.1 & 12.1 & 12.1 & 12.1 \\
\hline
\end{tabular}

\subsection{Chemical Compositions and Physical Properties of POFA}

The specific gravity of POFA and OPC was assessed using Micromeritics AccuPyc1330 helium pycnometer, while median particle size and specific surface area were measured using a laser diffraction analyzer (MASTERSIZER). The percentage of unburned carbon in POFA was calculated utilizing CHNS device. In addition, the chemical compositions of the POFA and OPC were analyzed using X-ray fluorescence (X-RF) while the loss of ignition (LOI) of both materials was determined depending on the specifications ASTM C311 [18] and ASTM C114 [19], respectively.

\subsection{Workability, Workability Retention and Setting Times}

High-strength concrete workability of HSCu and HSCg was assessed by applying slump test depending on the classification ASTM C143/C143M [20], in addition applying compacting factor test depending on the classification BS 1881: part 103 [21]. The workability retention test was assessed by applying the slump test after completing the concrete mixing process that continued for 2 mins in the dry state then 3 mins after adding the water to ensure homogeneity of the concrete mixture. The initial workability retention test reading was determined after 7 mins of the addition of water to the mixture. During the testing process, the fresh concrete remixing was done for 30 seconds at every 5 mins interval among tests to ensure homogeneity of the concrete mixture. The slump retention measurements of $\mathrm{HSCg}$ and $\mathrm{HSCu}$ were recorded at the period of 30,60 and 90 mins after adding the mixing water. The slump tests retention was determined depending on the classification of ASTM C143/C143M [20]. For the initial and final setting time, the tests were carried out using the proctor device. The setting time test was applied on mortar mixture, which was collected by sieving freshly mixed concrete by a 5-mm sieve for removing coarse aggregate. Then, the mixture was prepared in a suitable mold for recording penetration proctor needle in mixture $25 \mathrm{~mm}$ depending on the classification of ASTM C403 [22] which was then measured. Fig. (2a, b and c) show the apparatus used in the assessment of fresh concrete properties.

\subsection{Compressive Strength}

The compressive strength was assessed using concrete compression machine depending on the classification of BS 1881:part 181 [23]. The test was conducted on 100x100x100 mm concrete cubes at the ages of 1, 3, 7 and 28 days .

\section{RESULTS AND DISCUSSION}

\subsection{Physical Properties and Chemical Compositions of POFA}

The physical properties of the OPC and POFA showed that the heat treatment and the grinding process undertaken led to improvement in the physical characteristics and chemical compositions of the POFA. In addition, applied heat treatment on POF did not change glassy phase or led to a chemical reaction, as shown in the examination of X-RD in 
Fig. (3) [24]. The median particle sizes of the OPC, GPOFA and UPOFA are 6.79, 2.45 and $2.06 \mu$ m respectively ; specific surface area is $0.785,1.694$ and $1.775 \mathrm{~m}^{2} / \mathrm{g}$ and the measured specific gravity is $3.16,2.51$ and 2.59 respectively. Thus, the UPOFA records about 16 and 70\% smaller median particle size than the GPOFA and OPC, respectively owing to post and pre-heated grinding processes. At the same time, the specific surface area (BET) of the GPOFA due to the proliferation of the carbon content is $82.3 \%$ and $96.4 \%$ greater than that of the UPOFA and OPC, respectively $[25,26]$. Identical results in the range between 16 to $136 \mathrm{~m}^{2} / \mathrm{g}$ of surface area of unburned carbon have been reported by other researchers [12]. On the other hand, the specific gravity of the UPOFA is $6.1 \%$ greater than GPOFA, and $22.0 \%$ less than that of OPC [27].

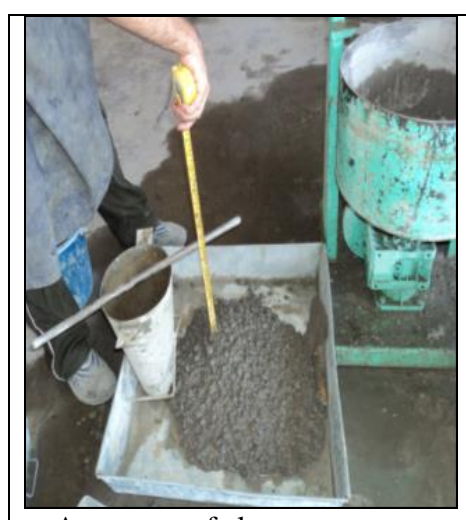

a: Apparatus of slump test

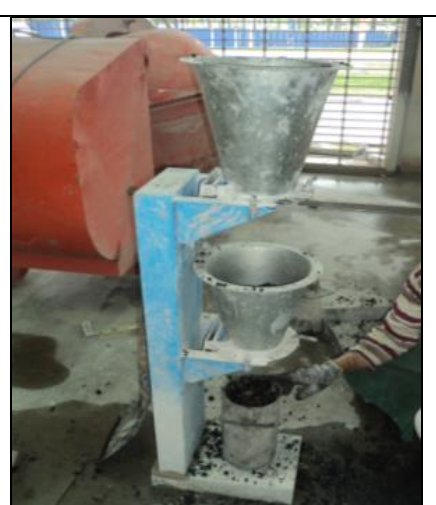

b: Apparatus of compacting factor test

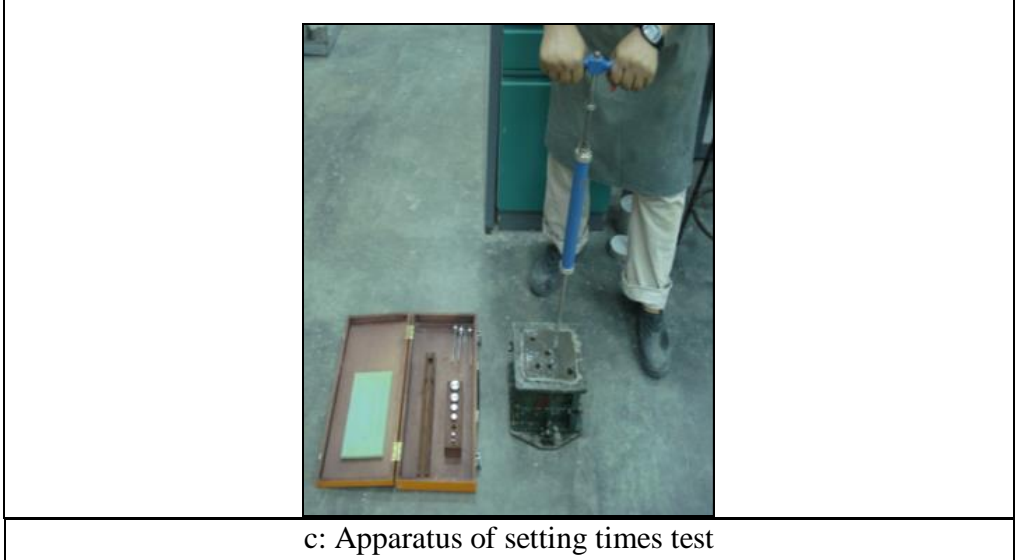

Fig. (2). Apparatus and equipment for slump, compacting factor and setting time test.

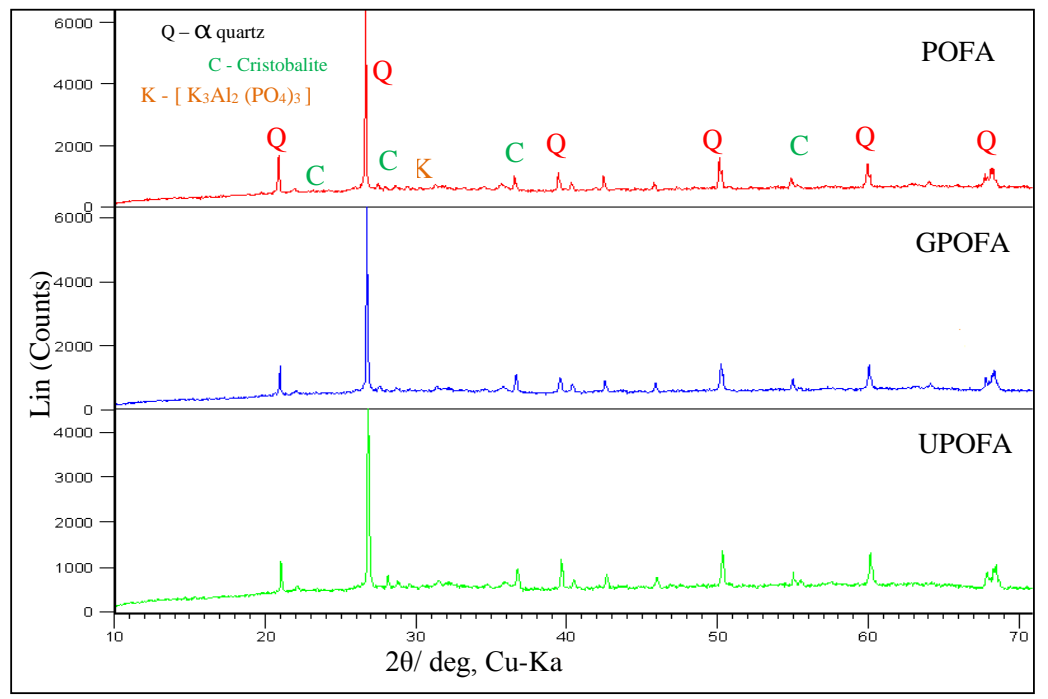

Fig. (3). X-RD diffractograms of POFA. 
The chemical compositions as shown in Table 3 also undergo changes due to the heat treatment and the subsequent grinding. Comparing the GPOFA with the UPOFA, it is obvious that the carbon content reduced from 18.9 to $0.041 \%$, and the LOI reduced from 15.34 to 2.53\%. Further, the sum of $\mathrm{SiO}_{2}, \mathrm{Al}_{2} \mathrm{O}_{3}$ and $\mathrm{Fe}_{2} \mathrm{O}_{3}$ (SAF) in UPOFA increases from about $59 \%$ to $75 \%$, respectively. Therefore, the resulting UPOFA can be classified as class $\mathrm{F}$ mineral admixture, according to ASTM C618 [28]. Consequently, the heat treatment process is very important to ensure acquiescence of the POFA with the LOI requirement specified in ASTM C618. The SEM with EDX clearly reflects the reduced carbon content of UPOFA compared to GPOFA (Fig. 4a, b), this was due to heat treatment of the G-POFA.

Table 3. Chemical compositions of OPC, GPOFA and UPOFA.

\begin{tabular}{|c|c|c|c|}
\hline Comp. & $\begin{array}{c}\text { Cement } \\
\text { (\%) }\end{array}$ & $\begin{array}{c}\text { GPOFA } \\
\text { (\%) }\end{array}$ & $\begin{array}{c}\text { UPOFA } \\
\text { (\%) }\end{array}$ \\
\hline $\mathrm{SiO}_{2}$ & 21.01 & 51.18 & 65.01 \\
\hline $\mathrm{Al}_{2} \mathrm{O}_{3}$ & 4.68 & 3.61 & 5.72 \\
\hline $\mathrm{Fe}_{2} \mathrm{O}_{3}$ & 3.20 & 6.93 & 4.41 \\
\hline $\mathrm{CaO}$ & 64.89 & 4.02 & 4.19 \\
\hline $\mathrm{MgO}$ & 0.81 & 4.1 & 4.58 \\
\hline $\mathrm{P}_{2} \mathrm{O}_{5}$ & 0.079 & 5.52 & 6.48 \\
\hline $\mathrm{K}_{2} \mathrm{O}$ & 1.17 & 0.36 & 0.33 \\
\hline $\mathrm{SO}_{3}$ & 3.66 & 0.19 & 0.25 \\
\hline $\mathrm{TiO}_{2}$ & 0.22 & 0.093 & 0.11 \\
\hline $\mathrm{MnO}$ & 0.19 & 0.056 & 0.07 \\
\hline $\mathrm{Na}_{2} \mathrm{O}$ & 0.086 & 18.9 & 0.041 \\
\hline $\mathrm{C}$ & - & 15.34 & 2.53 \\
\hline $\mathrm{LOI}_{750}{ }_{\mathrm{c}}$ & & - & - \\
\hline $\mathrm{LOI}_{950}{ }_{\mathrm{c}}$ & 2.48 & 59.21 & 75.14 \\
\hline $\mathrm{SiO}_{2}+\mathrm{Al}_{2} \mathrm{O}_{3}+\mathrm{Fe}_{2} \mathrm{O}_{3}$ & & \\
\hline & & & \\
\hline
\end{tabular}

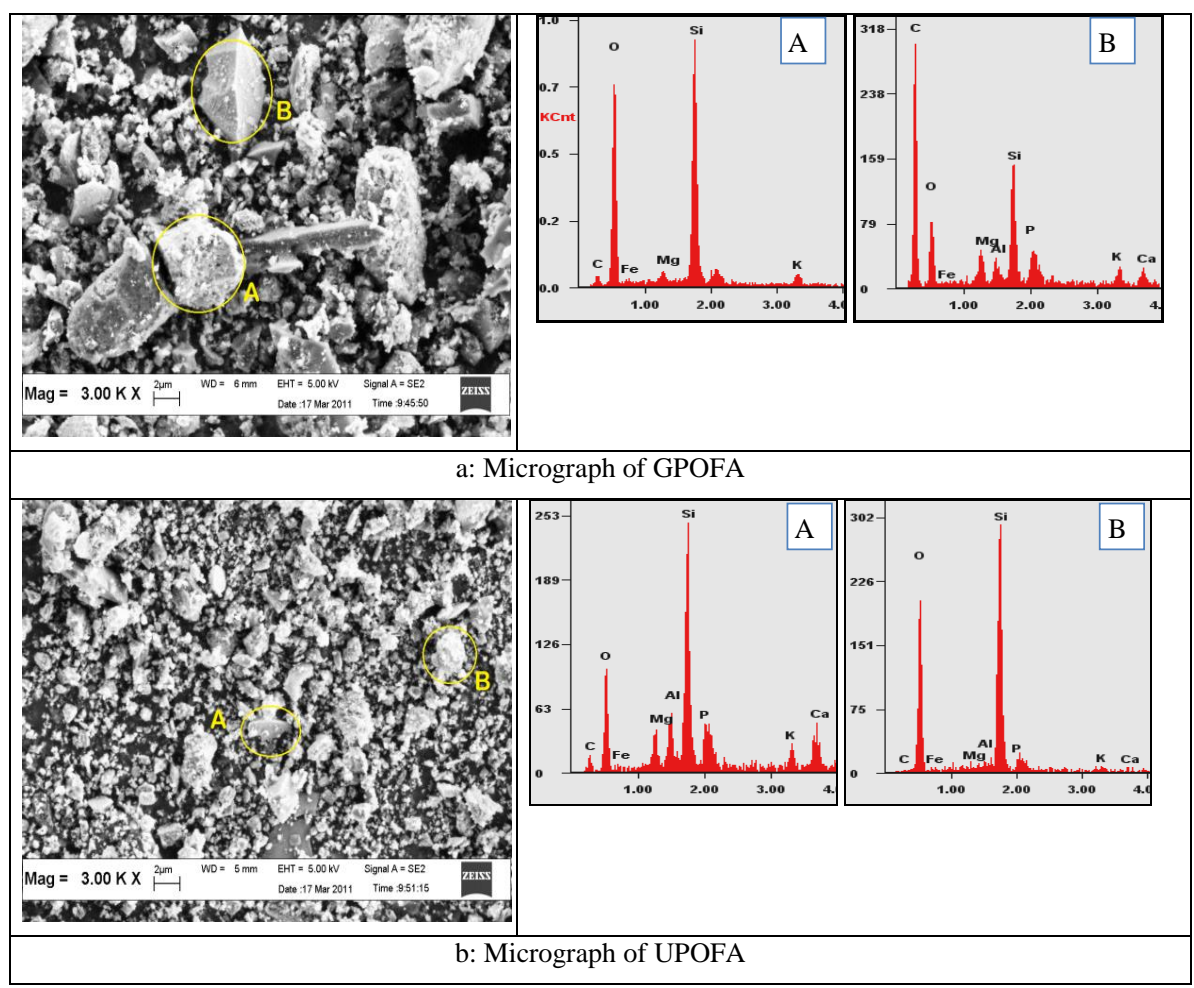

Fig. (4). Micrograph of palm oil fuel ash (POFA), a. Ground POFA b. Ultrafine POFA. 


\subsection{Effect of POFA on Workability}

The effect of both GPOFA and UPOFA on the workability of HSCg and HSCu assessed by means of slump test is shown in Fig. (5). It is clear that the increase in UPOFA content results in consistent improvement in slump. In comparison to the control mix (HSC-OPC), the HSCu exhibits an increase in slump of 11, 18 and 21\% for UPOFAcement substitution of 20, 40 and $60 \%$, respectively. For the $\mathrm{HSCg}$, the slump marginally increases by $5 \%$ in $\mathrm{HSCg}_{20} \%$ (20\% GPOFA-Cement substitution) in comparison with HSC-OPC (HSC) whereas it reduces by 5 and $37 \%$ in $\mathrm{HSCg}_{40} \%$ and $\mathrm{HSCg}_{60 \%}$, respectively.

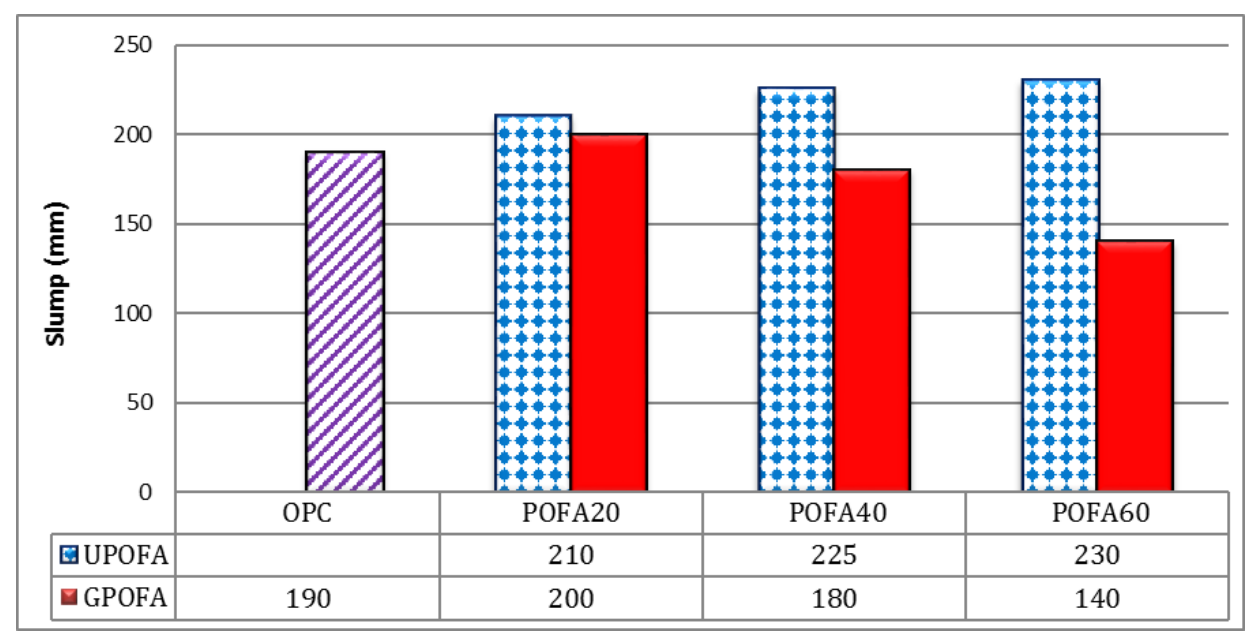

Fig. (5). Slump values in HSC-OPC, HSCu (UPOFA) and HSCg (GPOFA).

The different trend is due to the presence of unburned carbon that hinders the steric repulsion effect of the superplasticizer. The UPOFA, on the other hand, enhances workability via the greater paste volume that emanates from the lower specific gravity of UPOFA than OPC. Increase in paste volume provides an additional lubricating effect for the fresh concrete thereby the amount of energy is required to compact or enhance the flow of concrete to be reduced $[12,29]$.

Moreover, the compacting factor test results (Fig. 6) are similar to that of slump test, i.e. it increases the compacting factor of $\mathrm{HSCu}$ in comparison with the control HSC-OPC. In comparison with $\mathrm{HSC}-\mathrm{OPC}$, the values in $\mathrm{HSCu}_{20 \%}$ and $\mathrm{HSCu}_{40 \%}$ increased by $2.2 \%$ and $6.3 \%$, respectively. The compactor factor value reduced by $3.1 \%$, as UPOFA increased from 40 to $60 \%$ of OPC substitution. This validates the fact that $\mathrm{HSCu}$ workability increases as the POFA content reached $40 \%$.

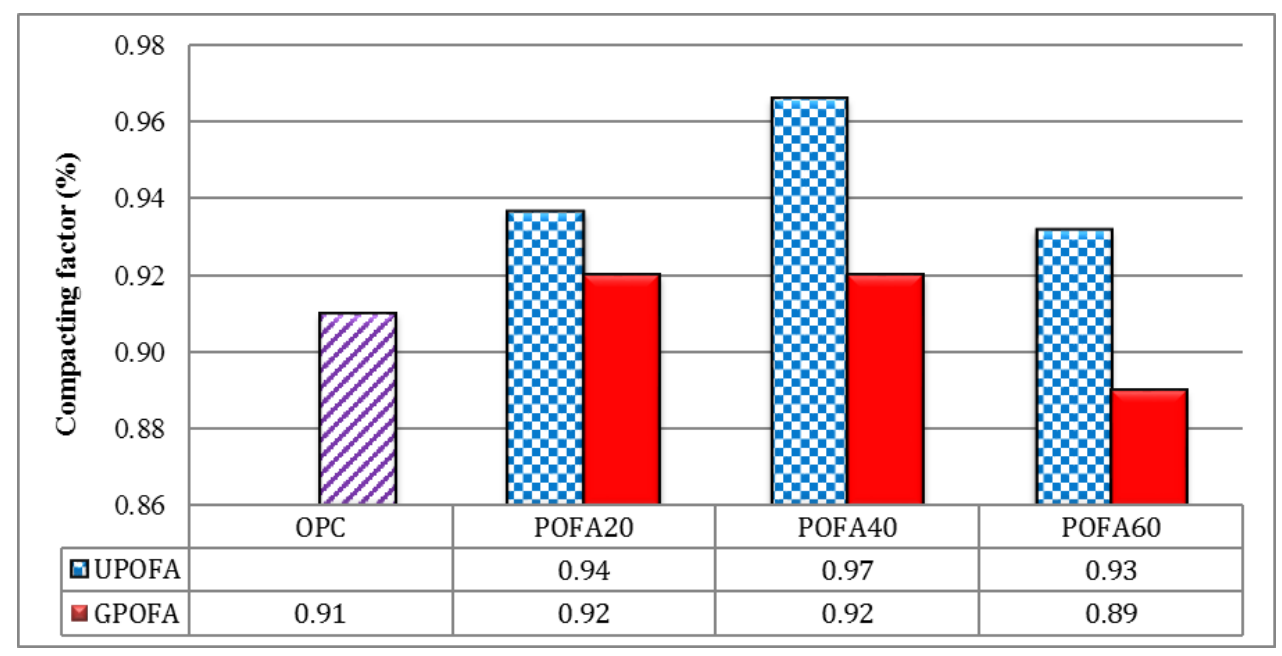

Fig. (6). Compacting factor in $\mathrm{HSC}-\mathrm{OPC}, \mathrm{HSCu}$ (UPOFA) and $\mathrm{HSCg}$ (GPOFA). 
However, the carbon content in HSCg caused a decrease in workability of the concrete as evident in Figs. (5 and $\mathbf{6})$. In comparison with HSC-OPC, the HSCg causes a slight increase in sample workability as against the significant impact noticed with $\mathrm{HSCu}$. This reduction is due to the fineness of the sample that is influenced by the presence of carbon content as evident in the surface area value. This causes an increase in the consistency or water demand of the concrete sample and decrease inter-particle lubrication and low workability. Hence, the POFA further treatment processes involving grinding and heating generally bring about positive effect in workability of the HSC.

\subsection{Effect of POFA on Workability Retention}

The influence of POFA on workability retention depending on measuring the loss in slump test with the passage of time is shown in Figs. (7 and 8) for $\mathrm{HSCu}$ and $\mathrm{HSCg}$, respectively. It is clear that for all of the HSC mixes, the workability retention reduces with time because of the chemical hydration reaction between the tricalcium aluminate $\left(\mathrm{C}_{3} \mathrm{~A}\right)$ in cement with water that promotes setting due to early exhaustion of gypsum in the early reaction of ettringite formation [13]. From Fig. (7), it is very evident that the addition of supplementary materials reduces the quantity of gypsum required to induced retardation or delay in setting thereby prompting the $\mathrm{C}_{3} \mathrm{~A}, \mathrm{C}_{2} \mathrm{~S}$ and $\mathrm{C}_{3} \mathrm{~S}$ reactivities. Hence, it causes strength development to commence due to the formation of strength skeleton $(\mathrm{C}-\mathrm{S}-\mathrm{H})$ with accompanied low workability retention.

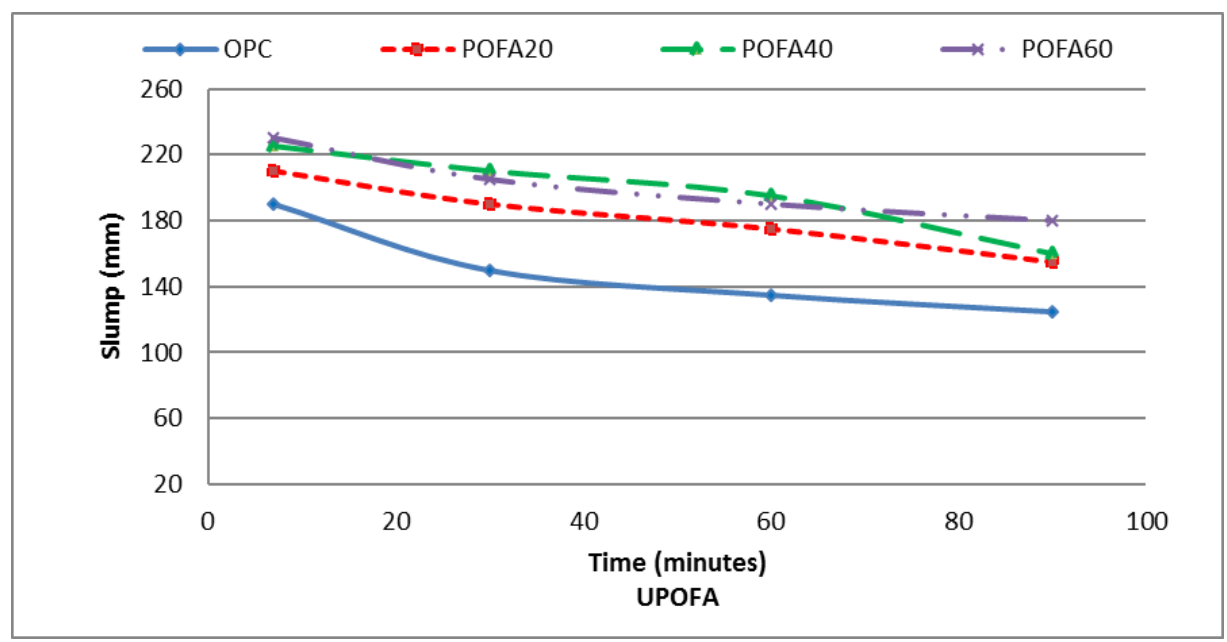

Fig. (7). Slump loss in High Strength Concrete Containing UPOFA (HSCu).

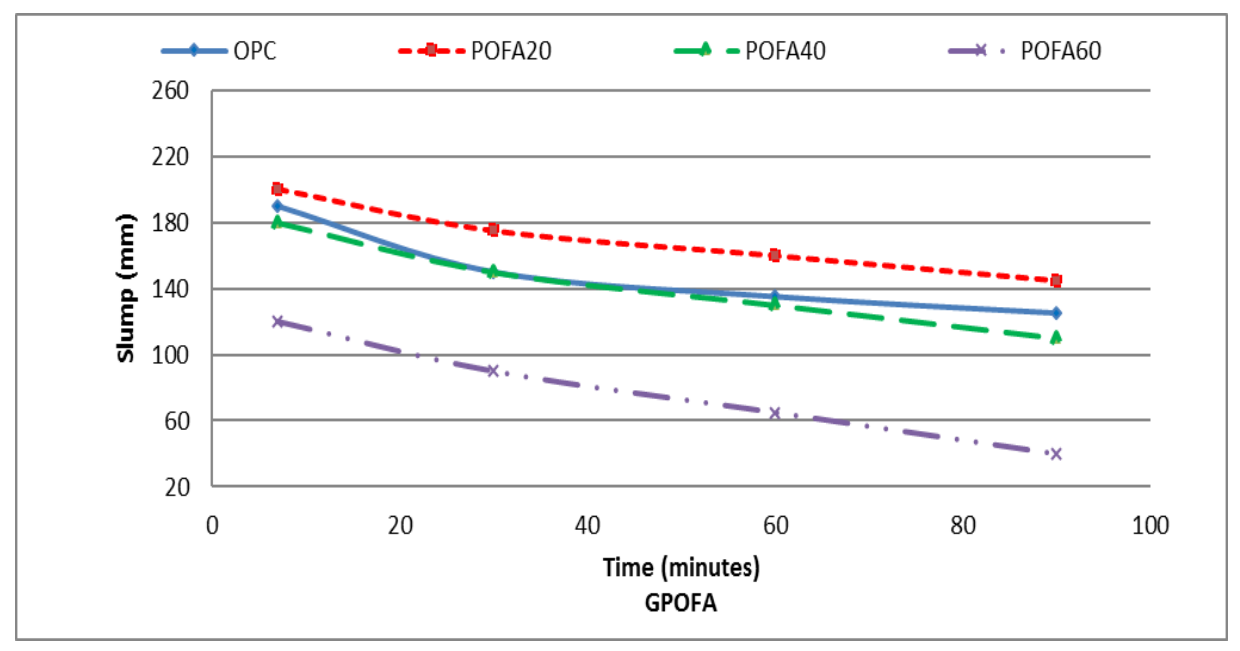

Fig. (8). Slump loss in High Strength Concrete Containing GPOFA (HSCg).

Increase in the quantity of cement replacement by POFA causes further increase in setting time that accompanies delay in hydration and pozzolanic reactions. Besides, at longer duration ( $90 \mathrm{mins})$, there is a little difference in workability retention between $\mathrm{HSCu}_{20 \%}$ and $\mathrm{HSCu}_{40 \%}$. Moreover, workability retention of $\mathrm{HSCu}_{60 \%}$ is greater than that of 
$\mathrm{HSCu}_{40 \%}$ by $12.5 \%$ at that specific reference time. Furthermore, the initial contribution of $60 \%$ UPOFA content to workability retention is lesser than that of early hour workability retention. Therefore, 60\% UPOFA-cement replacement is very beneficial for the extended concreting period (90 mins).

However, in Fig. (8), carbon composition appears to play major roles in the workability retention as the $60 \%$ cement substitution by GPOFA causes drastic fall in a slump because of unavailability of enough water for reaction to proceed due to carbon water absorption or adsorption. It can be observed that the initial slump reduction of around $31.8 \%$ is recorded in $\mathrm{HSCg}_{60 \%}$, and this increases further reduction to $70.8 \%$ after 90 mins, possibly due to further carbon water absorption tendency. In addition, as the GPOFA reduces to $40 \%$ substitution, the trend almost similar to HSC-OPC, while better retention is observed for $20 \%$ GPOFA-OPC substitution. This drives home the fact that the lower the carbon content in the mixture, the better the workability retention of a concrete mixture. For the HSCu, the recorded workability after 90 mins is $69,74,71$ and $78 \%$ with the corresponding initial workability of $0,20,40$ and $60 \%$ UPOFA-cement substitutions, respectively. This generally indicates that the inclusion of the UPOFA seems to marginally improve workability retention owing to a reduction in the $\mathrm{C}_{3} \mathrm{~A}$ proportion that accompanies $\mathrm{OPC}$ replacement. For the case of $\mathrm{HSCg}$, the retained workability after 90 mins is $69,73,61$ and $33 \%$ with the initial workability of $0,20,40$ and $60 \%$ GPOFA content. This clearly exhibits the significant influence of unburned carbon in GPOFA, which impairs workability retention due to the inefficiency of superplasticizer in the mixture as the content of GPOFA increases to $40 \%$ and $60 \%$ [30].

\subsection{Effect of POFA on Setting Times}

The results as shown in Figs. (9 and 10) clearly illustrate that the replacement of cement by both the UPOFA and GPOFA leads to considerable retardation in both the initial and final setting times, where the setting time extends at higher cement substitution levels. It is also important to observe the linear and non-linear relationship of setting with POFA-cement substitution in Figs. (9 and 10), respectively. The extension of setting time could be due to the reduction in the rate of production of ettringite resulting from gypsum reaction with water on one hand, and the hydration reaction that produces skeletal framework $(\mathrm{C}-\mathrm{S}-\mathrm{H})$ from alite $\left(\mathrm{C}_{3} \mathrm{~S}\right)$ and belite $\left(\mathrm{C}_{2} \mathrm{~S}\right)$ reactivities on the other. This is generally in agreement with the previous findings of [5] on HSC containing different supplementary cementitious materials.

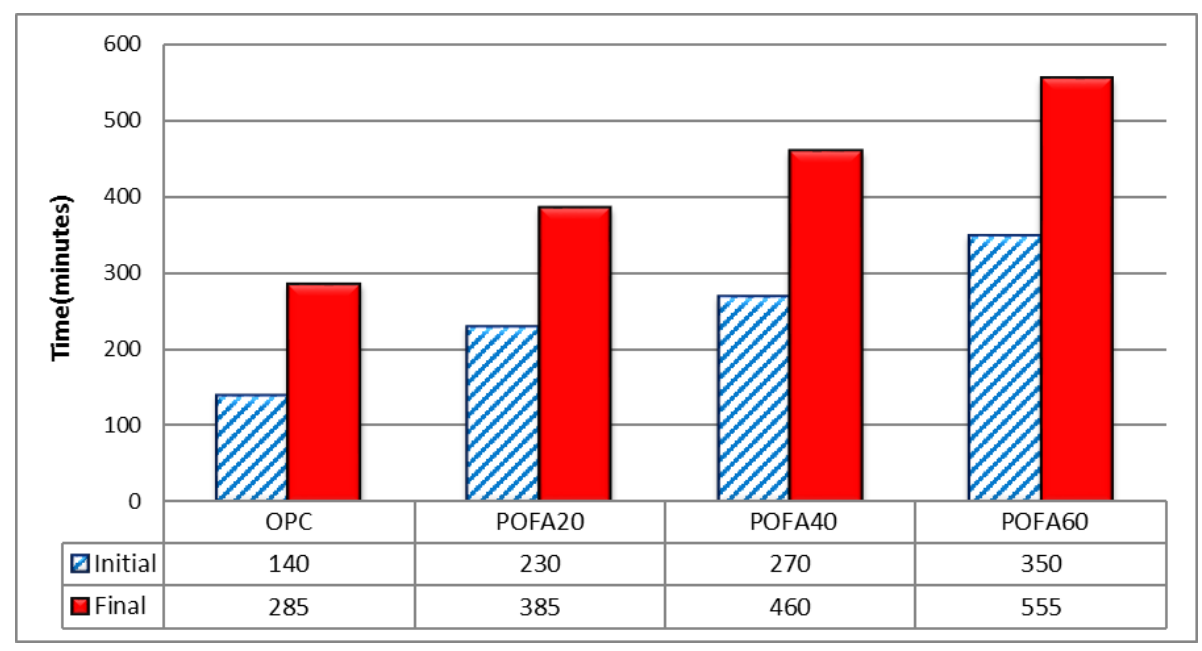

Fig. (9). Setting time in High Strength Concrete Containing UPOFA ( $\mathrm{HSCu}$ ).

Moreover, Tangchirapat et al. similar findings are also reported on concrete containing the POFA with different particle sizes. In addition, it is rather obvious that the retarding effect is greater in HSCu than HSCg owing to the superfluity of carbon in the later that inhibits the superplasticising effect of the high range water reducer. The reason for more delay in the setting of HSCu could be explained from the fact that portlandite that generates from hydration reaction reduces with cement content, while the rate of aftermath pozzolanic reaction reduces with carbon content and fineness of POFA particles. The percentage margin between initial and final setting time in HSCu (Fig. 9) increases by $3.33 \%, 46.15 \%, 86.36 \%$ for POFA-cement substitution of $20 \%, 40$ and $60 \%$, respectively when compared to HSCg (Fig. 10). This reveals the possibility of extended pozzolanic reaction in HSCu compared to HSCg for a similar level of cement substitution. 


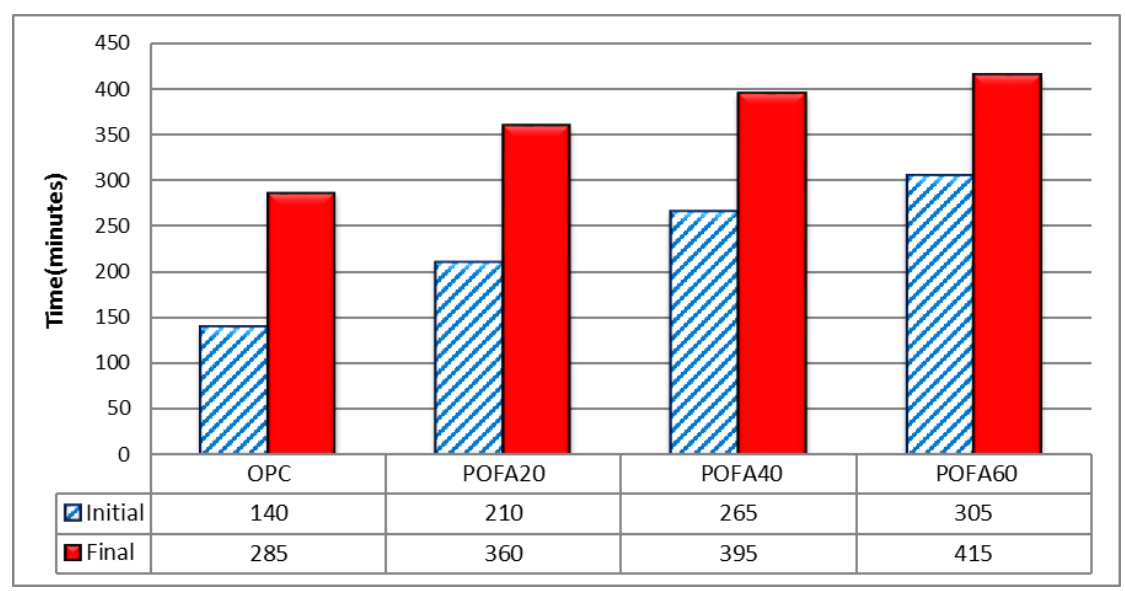

Fig. (10). Setting Time in High Strength Concrete Containing GPOFA (HSCg).

In general, the retardation of the concrete that contains SCMs is directly connected to its quantities in such mixture. The delay in the setting of HSC is very beneficial in that, it could be utilized to its advantage in hot weather concreting to moderate the effect of high ambiance temperature or rapid setting of concrete [31].

\subsection{Effect of POFA on Compressive Strength}

The results in Figs. (11 and 12) demonstrate the effect of inclusion of the UPOFA and GPOFA on the strength of $\mathrm{HSCu}$ and $\mathrm{HSCg}$, respectively. It is clear that the presence of POFA reduces early age strength of the HSC due to extended hydration reaction time in $\mathrm{HSCu} / \mathrm{g}$ compared to HSC-OPC due to less OPC content. The extension is caused by the delayed formation of C-S-H, which increases with more POFA content due to the dilution effect. At 1 day, the $\mathrm{HSCu}$ records a relative strength of $71.3,57.5$ and $41.1 \%$ of the $\mathrm{HSC}-\mathrm{OPC} \mathrm{HSCu}_{20 \%}, \mathrm{HSCu}_{40 \%}$ and $\mathrm{HSCu}_{60 \%}$, respectively. These respective relative strengths increase to $93.4,84.6$ and $64.1 \%$ at 3 days; and $100.6,97.7$, and $91.4 \%$ at 7 days. Subsequently, with prolonged curing in the water for 28 days, the HSCs exhibit greater strength than the HSC-OPC, the $\mathrm{HSCu}$ records a relative strength of $103.3,109$ and $107 \%$ for $\mathrm{HSCu}_{20 \%}, \mathrm{HSCu}_{40 \%}$, and $\mathrm{HSGCu}_{60 \%}$, respectively with the $\mathrm{HSCu}_{40 \%}$ exhibits the highest 28-day strength. Hence, all the $\mathrm{HSCu}$ samples achieve greater strength than the HSC-OPC at 180 days, with a compressive strength of 105.1, 108.6, 114.4 and 112.4 MPa recorded in HSC-OPC, $\mathrm{HSCu}_{20 \%}, \mathrm{HSCu}_{40 \%}$, and $\mathrm{HSGCu}_{60 \%}$, respectively. The increment in strength is caused by the occurrence of pozzolanic reactions of portlandite $\left(\mathrm{Ca}(\mathrm{OH})_{2}\right)$ formed in the aftermath of hydration reaction with silica $\left(\mathrm{SiO}_{2}\right)$ compositions of POFA. This reaction leads to the formation of secondary hydration products (C-S-H) at a faster rate than possible at early days due to less presence of portlandite [32,33]. The similar effect is observed in Fig. (12) on the strength development of HSCg.

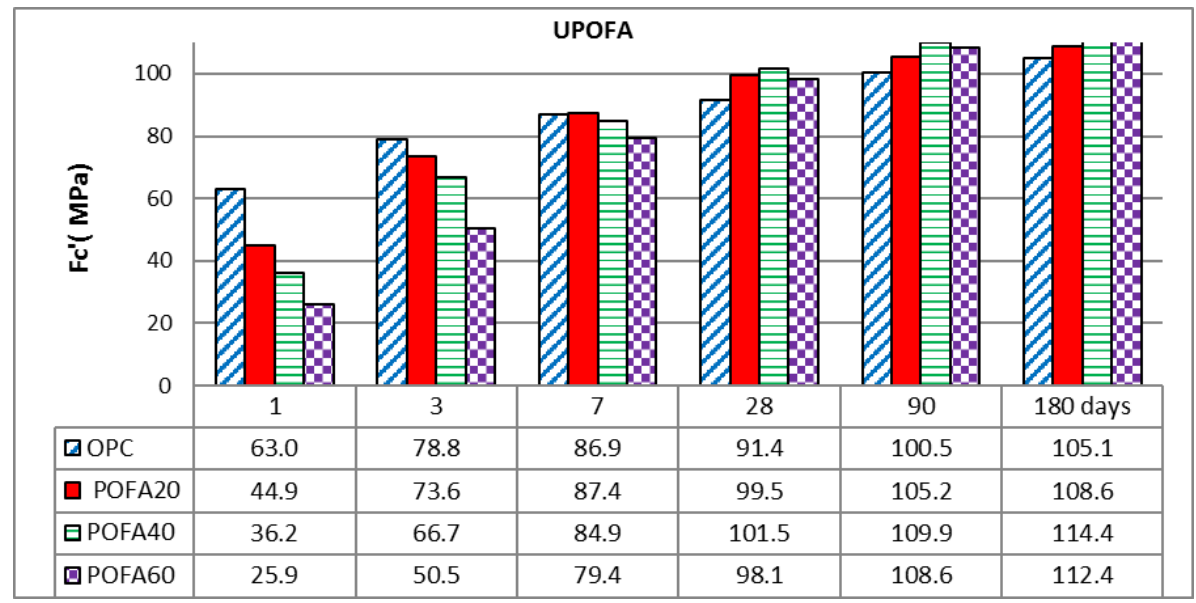

Fig. (11). Compressive strength of High Strength Concrete Containing UPOFA (HSCu). 


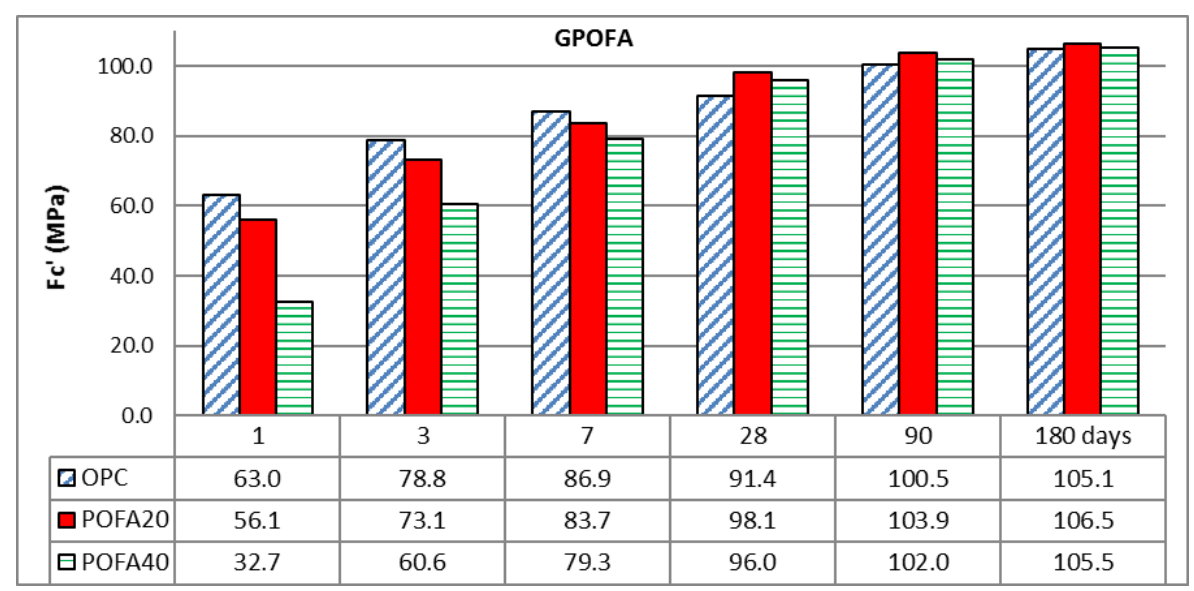

Fig. (12). Compressive strength of High Strength Concrete Containing GPOFA (HSCg).

However, for the $\mathrm{HSCg}_{60 \%}$, proper casting and compacting could not be achieved because of the rapid slump loss; thus, no strength data is available for this mix. However, the results at 1 day for the $\mathrm{HSCg}_{20 \%}$ and $\mathrm{HSCg}_{40 \%}$ exhibit a relative strength of $89 \%$ and $52 \%$, respectively in comparison with HS-OPC. The respective relative strength increases by $92 \%$ and $77 \%$ at 7 days, and subsequently to 107 and $105 \%$ at 28 days. Hence, all the HSCu samples achieve greater strength than the HSC-OPC at 180 days, with a compressive strength of 105.1, 106.5 and 105.5 MPa recorded in HSC$\mathrm{OPC}, \mathrm{HSCg}_{20 \%}$ and $\mathrm{HSCg}_{40 \%}$ respectively. The fact is that unburned carbon does not significantly hamper strength development at a later concrete age of HSCg. Therefore, in the concrete where concrete durability is not of a major concern, it will be quite economical to employ the use of GPOFA based high strength green concrete (HSCg) due to the reduction in the cost of post POFA treatments that include heat treatments and subsequent grinding process.

\section{CONCLUSION}

Based on the results of the present study on workability, setting and compressive strength of highest concrete containing carbon-laden ground palm oil fuel ash ( $\mathrm{HSCg}$ ) and carbon-free ultrafine or treated palm oil fuel ash ( $\mathrm{HSCu}$ ) were investigated, and the following conclusions are drawn:

1. Further treatment of ground palm oil fuel ash led to improvement of the material physical and chemical properties with an improved loss on ignition (LOI) reduced carbon content and enhanced amorphous phase of chemical composition.

2. Carbon content reduction in POFA due to heat treatment influenced the workability retention, setting time and strength positively. This was evident in the better performance of $\mathrm{HSCu}$ in comparison with $\mathrm{HSCg}$. Similarly, workability retention increased with UPOFA composition. This is evident in $\mathrm{HSCu}_{60 \%}$, which had $12.5 \%$ and $46.3 \%$ greater workability retention than $\mathrm{HSCu}_{40 \%}$ and $\mathrm{HSC}-\mathrm{OPC}$ or $\mathrm{HSCu}_{0 \%}$, respectively.

3. Low specific gravity of POFA had positive impacts on the workability of the resulting HSC due to the propensity of generating more paste volume and more lubricating effect that resulted into low compactive energy, while its carbon content and fineness could affect it negatively.

4. More POFA composition delays the setting times of the HSC by slowing down the hydration rate due to the influence of pozzolanic reaction, while carbon content aggravated this tendency. Hence, UPOFA induced a greater retarding effect on the resulting HSC.

5. UPOFA and GPOFA lowered the early age compressive strength in HSC (up to 7 days), but contributed significantly to the strength beyond 180 days, due to the enhanced pozzolanic reactivity that generated additional or secondary C-S-H.

\section{CONSENT FOR PUBLICATION}

Not applicable 


\section{CONFLICT OF INTEREST}

The authors declare no conflict of interest, financial or otherwise.

\section{ACKNOWLEDGEMENTS}

Declared none.

\section{REFERENCES}

[1] ACI, “Control of Cracking in Concrete Structures, ” in ACI., 224th ed American Concrete Institute: Farmington Hills, MI, 2001 , p. 46.

[2] A.A. Almusallam, "Effect of environmental conditions on the properties of fresh and hardened concrete", Cement Concr. Compos., vol. 23, pp. 353-361, 2001.

[http://dx.doi.org/10.1016/S0958-9465(01)00007-5]

[3] K. Muthusamy, and N. Zamri, "Mechanical properties of oil palm shell lightweight aggregate concrete containing palm oil fuel ash as partial cement replacement", KSCE J. Civ. Eng., pp. 1-9, 2015.

[4] A.N. Mohammed, M. Azmi Megat Johari, A.M. Zeyad, B.A. Tayeh, and M.O. Yusuf, "Improving the engineering and fluid transport properties of ultra-high strength concrete utilizing ultrafine palm oil fuel ash", J. Adv. Concr. Technol., vol. 12, pp. 127-137, 2014. [http://dx.doi.org/10.3151/jact.12.127]

[5] J. Brooks, M.J. Megat Azmi, and M. Mazloom, "Effect of admixtures on the setting times of high-strength concrete", Cement Concr. Compos., vol. 22, pp. 293-301, 2000. [http://dx.doi.org/10.1016/S0958-9465(00)00025-1]

[6] Ş. Erdogdu, "Effect of retempering with superplasticizer admixtures on slump loss and compressive strength of concrete subjected to prolonged mixing", Cement Concr. Res., vol. 35, pp. 907-912, 2005. [http://dx.doi.org/10.1016/j.cemconres.2004.08.020]

[7] M.O. Yusuf, M.A. Megat Johari, Z.A. Ahmad, and M. Maslehuddin, "Evaluation of slag-blended alkaline-activated Palm oil fuel ash mortar exposed to the sulfuric acid environment", J. Mater. Civ. Eng., vol. 27, p. 04015058, 2015. [http://dx.doi.org/10.1061/(ASCE)MT.1943-5533.0001315]

[8] W. Kroehong, N. Damrongwiriyanupap, T. Sinsiri, and C. Jaturapitakkul, "The Effect of Palm Oil Fuel Ash as a Supplementary Cementitious Material on Chloride Penetration and Microstructure of Blended Cement Paste", Arab. J. Sci. Eng., vol. •••, pp. 1-10, 2016.

[9] M.J. Megat Azmi, J. Brooks, S. Kabir, and P. Rivard, "Influence of supplementary cementitious materials on engineering properties of high strength concrete", Constr. Build. Mater., vol. 25, pp. 2639-2648, 2011. [http://dx.doi.org/10.1016/j.conbuildmat.2010.12.013]

[10] A.M. Zeyad, M.A.M. Johari, B.A. Tayeh, and M.O. Yusuf, "Pozzolanic reactivity of ultrafine palm oil fuel ash waste on strength and durability performances of high strength concrete", J. Clean. Prod., vol. 144, pp. 511-522, 2017. [http://dx.doi.org/10.1016/j.jclepro.2016.12.121]

[11] A. Zeyad, M.M. Johari, B. Tayeh, and M.O. Yusuf, "Efficiency of treated and untreated palm oil fuel ash as a supplementary binder on engineering and fluid transport properties of high-strength concrete", Constr. Build. Mater., pp. 1066-1079, 2016. [http://dx.doi.org/10.1016/j.conbuildmat.2016.08.065]

[12] C. Chandara, E. Sakai, K.A.M. Azizli, Z.A. Ahmad, and S.F.S. Hashim, "The effect of unburned carbon in palm oil fuel ash on fluidity of cement pastes containing superplasticizer", Constr. Build. Mater., vol. 24, pp. 1590-1593, 2010. [http://dx.doi.org/10.1016/j.conbuildmat.2010.02.036]

[13] S. Chandra, and J. Bjornstrom, "Influence of superplasticizer type and dosage on the slump loss of Portland cement mortars--Part II", Cement Concr. Res., vol. 32, pp. 1613-1619, 2002. [http://dx.doi.org/10.1016/S0008-8846(02)00838-4]

[14] A. M. Zeyad, "Effect of curing methods in hot weather on the properties of high-strength concretes", Journal of King Saud University Engineering Sciences, 2017.

[http://dx.doi.org/10.1016/j.jksues.2017.04.004]

[15] M.J. Megat Azmi, A. Zeyad, N. Muhamad Bunnori, and K. Ariffin, "Engineering and transport properties of high-strength green concrete containing high volume of ultrafine palm oil fuel ash", Constr. Build. Mater., vol. 30, pp. 281-288, 2012. [http://dx.doi.org/10.1016/j.conbuildmat.2011.12.007]

[16] ASTM, "Standard Specification for Portland Cement " in ASTM C., 150th ed American Society for Testing and Materials: West Conshohocken, 2001, p. 5.

[17] E.G. Nawy, Fundamentals of High Strength High Performance Concrete Concrete, Longman: Desigen and construction Series, 1996 , p. 335.

[18] ASTM, "Standard Test Methods for Sampling and Testing Fly Ash or Natural Pozzolans for Use as a Mineral Admixture in Portland-Cement Concrete", in ASTM C311 ed. West Conshohocken: American Society for Testing and Materials, 1998, p. 8.

[19] ASTM, "Standard Test Methods for Chemical Analysis of Hydraulic Cement", in ASTM C114, ed. West Conshohocken: American Society for Testing and Materials, 2000, p. 30. 
[20] ASTM, "Standard Test Method for Slump of Hydraulic-Cement Concrete", in ASTM C143/C143M ed. West Conshohocken: 100 Barr Harbor, 1998 , p. 3.

[21] BS, "Method for determination of compacting factor", in BS 1881: Part 103, ed. London: British Standards Institution, 1993.

[22] C. ASTM, "Standard test method for time of setting of concrete mixture by penetration resistance", in $A S T M C 403 / C 403 / M$., ed. West Conshohocken: American Society for Testing and Materials, 1999, pp. 217-221.

[23] BS, Method for making test cubes from fresh concrete Licensed in BS 1881-108:1983, ed. London, UK: BSI, 2002, p. 11

[24] A.M. Zeyad, "Influence of Steam Curing on Engineering and Fluid Transport Properties of High Strength Green Concrete Containing Palm Oil Fuel Ash", PhD thesis, Universiti Sains Malaysia, Penang, Malaysia, 2013.

[25] P.A. Gauden, A.P. Terzyk, S. Furmaniak, P.J.F. Harris, and P. Kowalczyk, "BET surface area of carbonaceous adsorbents--Verification using geometric considerations and GCMC simulations on virtual porous carbon models", Appl. Surf. Sci., vol. 256, pp. 5204-5209, 2010. [http://dx.doi.org/10.1016/j.apsusc.2009.12.097]

[26] N. Passe-Coutrin, S. Altenor, D. Cossement, C. Jean-Marius, and S. Gaspard, "Comparison of parameters calculated from the BET and Freundlich isotherms obtained by nitrogen adsorption on activated carbons: A new method for calculating the specific surface area", Microporous Mesoporous Mater., vol. 111, pp. 517-522, 2008. [http://dx.doi.org/10.1016/j.micromeso.2007.08.032]

[27] K.H. Pedersen, A.D. Jensen, M.S. Skjøth-Rasmussen, and K. Dam-Johansen, "A review of the interference of carbon containing fly ash with air entrainment in concrete", Pror. Energy Combust. Sci., vol. 34, pp. 135-154, 2008. [http://dx.doi.org/10.1016/j.pecs.2007.03.002]

[28] ASTM, “Standard Specification for Fly Ash or Raw or Natural Pozzolan for Use as a Mineral Admixture in Portland Cement Concrete,” in ASTM C618., 2005, p. 4.

[29] D. Ravina, "Properties of fresh concrete incorporating a high volume of fly ash as partial fine sand replacement", Mater. Struct., vol. 30, pp. 473-479, 1997.

[http://dx.doi.org/10.1007/BF02524775]

[30] S.H. Lee, H.J. Kim, E. Sakai, and M. Daimon, "Effect of particle size distribution of fly ash-cement system on the fluidity of cement pastes", Cement Concr. Res., vol. 33, pp. 763-768, 2003. [http://dx.doi.org/10.1016/S0008-8846(02)01054-2]

[31] B. Ahmadi, "Initial and final setting time of concrete in hot weather", Mater. Struct., vol. 33, pp. 511-514, 2000. [http://dx.doi.org/10.1007/BF02480528]

[32] M. Safiuddin, M.A. Salam, and M.Z. Jumaat, "Utilization of palm oil fuel ash in concrete: a review", J. Civ. Eng. Manag., vol. 17, pp. 234-247, 2011. [http://dx.doi.org/10.3846/13923730.2011.574450]

[33] B.A. Tayeh, B. Abu Bakar, M. Johari, and A. Zeyad, "The role of silica fume in the adhesion of concrete restoration systems", Adv. Mat. Res., pp. 265-269, 2013.

(C) 2018 Zeyad et al.

This is an open access article distributed under the terms of the Creative Commons Attribution 4.0 International Public License (CC-BY 4.0), a copy of which is available at: https://creativecommons.org/licenses/by/4.0/legalcode. This license permits unrestricted use, distribution, and reproduction in any medium, provided the original author and source are credited. 